\title{
Restriction Endonuclease Analyses of Two Porcine Mycoplasma Deoxyribonucleic Acids: Sequence-Specific Methylation in the Mycoplasma hyopneumoniae Genome $\dagger$
}

\author{
HARDY W. CHAN ${ }^{1 *}$ AND RICHARD F. ROSS ${ }^{2}$ \\ Recombinant DNA Section, Institute of Bio-Organic Chemistry, Syntex Research, Palo Alto, California $94304^{1}$ and \\ Veterinary Medical Research Institute, Iowa State University, Ames, Iowa $50011^{2}$
}

\begin{abstract}
The deoxyribonucleic acids of two porcine mycoplasmas, Mycoplasma hyopneumoniae and Mycoplasma flocculare, were distinguished readily with restriction enzymes. Enzymes that recognized guanine-pluscytosine-rich sequences, such as $S m a I$ and $B a m H I$, were particularly useful since they generated relatively small numbers of deoxyribonucleic acid fragments which could be resolved by gel electrophoresis. In addition, we found that the adenine nucleotide in the GATC sequence of $M$. hyopneumoniae is methylated, whereas that in $M$. flocculare is not.
\end{abstract}

Identification and classification of mycoplasmas have been difficult due to the scarcity of available biochemical assays, which have been limited to a few serological tests. Recently, Bové and Saillard (3) proposed a new approach to classification of mycoplasmas based on the use of restriction endonucleases. Characterization of bacterial plasmids or viral genomes by using restriction endonucleases has become a standard and indispensable tool in modern molecular biology. Unfortunately, when the much larger genomes of bacteria are digested with restriction enzymes, there are too many deoxyribonucleic acid (DNA) fragments generated for clear separation by gel electrophoresis. The average genome size of mycoplasmas is between 750 and 1,400 kilobases (17), which is smaller than the genomes of most known bacteria, and thus the DNAs of mycoplasmas are amenable to restriction enzyme analysis $(20,21)$.

In this study, DNAs from Mycoplasma hyopneumoniae and Mycoplasma flocculare were compared by using a number of restriction endonucleases. These two mycoplasma species are common isolates from porcine respiratory tracts; $M$. hyopneumoniae is the primary agent in mycoplasmal pneumonia of swine, whereas $M$. flocculare is considered nonpathogenic. In addition to having the same habitat, $M$. hyopneumoniae and $M$. flocculare are glycolytic and on agar generally form colonies without central zones (27). Although these two species can be distinguished by certain serological tests (25), analysis by crossed-immunoelectrophoresis has shown that they are more closely related to one another than is usual among glycolytic mycoplasmas $(\mathrm{L}$. H. Ro and R. F. Ross, Am. J. Vet. Res., in press). Because of their close serological relatedness, additional characteristics that distinguish these two species would be of considerable taxonomic and diagnostic value. In the work reported here, we found that $M$. hyopneumoniae and $M$. flocculare indeed can be distinguished by restriction enzyme digestion. Moreover, we found that the adenine nucleotide in the GATC sequence of $M$. hyopneumoniae is methylated, whereas that in $M$. flocculare is not.

\footnotetext{
* Corresponding author.

$\dagger$ This paper is contribution 175 from the Institute of Bio-Organic Chemistry, Syntex Research, Palo Alto, Calif.
}

\section{MATERIALS AND METHODS}

Cells. $M$. hyopneumoniae strains $\mathrm{J}^{\mathrm{T}}\left(=\right.$ ATCC $\left.25934^{\mathrm{T}}\right) ; \mathrm{T}$ = type strain) (passage 52), 11 (passage 20), 1361A (passage 13 ), and $1375 \mathrm{c}$ (passage 11 ) and $M$. flocculare ATCC $27399^{\mathrm{T}}$ were cultivated in Friis medium (9) supplemented with $1 \%$ dextrose. The organisms were incubated in stationary cultures at $37^{\circ} \mathrm{C}$ until color change and turbidity were observed. Samples were examined microscopically and passaged into blood agar to assure that no bacteria were present. The cells were harvested by centrifugation at $16,000 \times g$ for $30 \mathrm{~min}$ and were washed twice by centrifugation at $12,000 \times g$ for 15 min with $0.25 \mathrm{M} \mathrm{NaCl}-0.01 \mathrm{M} \mathrm{MgCl}_{2}$. The pellets were frozen at $-70^{\circ} \mathrm{C}$.

Preparation of mycoplasmal DNAs. Mycoplasmal DNAs were prepared by modifying the procedure of CeroneMcLernon and Furness (4). Briefly, frozen mycoplasma cells were suspended in $25 \mathrm{ml}$ of cold $0.1 \mathrm{M} \mathrm{NaCl}-0.01 \mathrm{M}$ ethylenediaminetetraacetate buffer ( $\mathrm{pH} 8.5$ ) containing 0.2 $\mu \mathrm{g}$ of ribonuclease per $\mathrm{ml}$. A $1 \mathrm{M}$ tris(hydroxymethyl)aminomethane hydrochloride solution ( $\mathrm{pH} 9.0$ ) containing $10 \%$ sodium dodecyl sulfate was added to give a final concentration of $1 \%$ sodium dodecyl sulfate. The cells were lysed, and the ribonucleic acid was destroyed by incubating the mixture at $37^{\circ} \mathrm{C}$ for $30 \mathrm{~min}$. The lysates were then extracted twice with equal volumes of phenol. The mixture was then centrifuged, and the upper aqueous phase was removed. The aqueous phase was extracted twice with chloroform; 2.5 volumes of ice-cold $95 \%$ ethanol was added to the aqueous phase to precipitate the DNA. The DNA precipitate was suspended in buffer containing $10 \mathrm{mM}$ tris(hydroxymethyl)aminomethane hydrochloride $(\mathrm{pH} \mathrm{7.4)}$ and $0.1 \mathrm{mM}$ ethylenediaminetetraacetate.

Preparation of $M$. hyopneumoniae-infected bronchial specimens. Yorkshire-Hampshire cross-bred pigs 8 weeks old were obtained from a disease-free herd maintained at Iowa State University. The pigs were inoculated intratracheally with an $M$. hyopneumoniae pneumonic lung inoculum (W. Amanfu et al., Am. J. Vet. Res., in press); 32 days after inoculation the animals were necropsied. Pneumonia typical of enzootic pneumonia was observed in the lungs of all of the pigs inoculated with $M$. hyopneumoniae. Lung washings were collected by flushing the airways of the left lung 
(bronchus and bronchioles) with $50 \mathrm{ml}$ of saline. DNAs were prepared from the lung washings by a standard sodium dodecyl sulfate-phenol extraction procedure.

Restriction enzyme digestion of DNA. All restriction endonucleases were purchased from New England BioLabs or Bethesda Research Laboratories, Inc. The reaction conditions used were the conditions specified by the suppliers. Restriction fragments were separated by electrophoresis on $0.7 \%$ agarose gels. The running tris(hydroxymethyl)aminomethane-borate buffer ( $\mathrm{pH} 8.2$ ) contained $89 \mathrm{mM}$ tris(hydroxymethyl)aminomethane, $89 \mathrm{mM}$ boric acid, and $2.5 \mathrm{mM}$ ethylenediaminetetraacetate.

Southern blot analyses of DNAs. DNA samples cleaved with the appropriate enzymes were separated by electrophoresis on $0.7 \%$ agarose gels. The restriction fragments were then denatured in situ and blotted onto nitrocellulose filters by the procedure of Southern (26), as modified by Jeffreys and Flavell (13). The blotted nitrocellulose filters were soaked in $3 \times$ SSC containing $10 \times$ Denhardt solution (5) for 2 $\mathrm{h}$ at $60^{\circ} \mathrm{C}(1 \times \mathrm{SSC}$ is $150 \mathrm{mM}$ sodium chloride plus $15 \mathrm{mM}$ sodium citrate). DNA from an arbitrarily chosen recombinant plasmid, which contained a 9-kilobase HindIII fragment insertion of $M$. hyopneumoniae DNA, was radioactively labeled by using a standard nick-translation procedure (22). The filters were hybridized against the radioactively labeled probe and washed as described previously (12). After air drying, the filters were exposed to Kodak XAR-2 X-ray film to detect the hybridized probe.

Molecular cloning of $M$. hyopneumoniae DNA. M. hyopneumoniae strain $\mathrm{J}^{\mathrm{T}}$ DNA was cleaved with HindIII. The DNA digest was ligated to plasmid pBR322 (2) DNA which had been cleaved with HindIII and treated with calf intestine alkaline phosphatase. Competent Escherichia coli strain HB101 cells were transformed with the ligation mixture by using the standard $\mathrm{CaCl}_{2}$ procedure (14). Ampicillin-resistant, tetracycline-susceptible colonies were selected.

\section{RESULTS}

Restriction enzyme digestion of $M$. hyopneumoniae and $M$. flocculare DNAs. The results obtained after cleavage of $M$. hyopneumoniae and $M$. flocculare DNAs with SmaI (CCCGGG), BamHI (GGATCC), HindIII (AAGCTT), EcoRI (GAATTC), BclI (TGATCA), and $M s p$ I or HpaII (CCGG) are shown in Fig. 1. Although all of the enzymes generated restriction patterns that readily distinguished the two species, better resolution of low-molecular-weight DNA fragments was obtained with enzymes that recognize guanine-plus-cytosine-rich sequences (e.g., SmaI and BamHI) than with enzymes that recognize adenine-plus-thymine-rich sequences (EcoRI and HindIII). Cleavage with $M s p I$ or HpalI (23), enzymes which recognize the tetranucleotide CCGG, also generated DNA fragments of the two species that could be resolved easily.

DNA methylation in $M$. hyopneumoniae. DNA from $M$. hyopneumoniae was completely resistant to digestion by $B c / I$ (Fig. 1), suggesting that it was methylated (1). In contrast, DNA from $M$. flocculare was quite susceptible to $B c l$ l cleavage. Figure 2 shows the patterns obtained by digesting DNAs from $M$. hyopneumoniae strain $\mathrm{J}^{\mathrm{T}}$ and $M$.
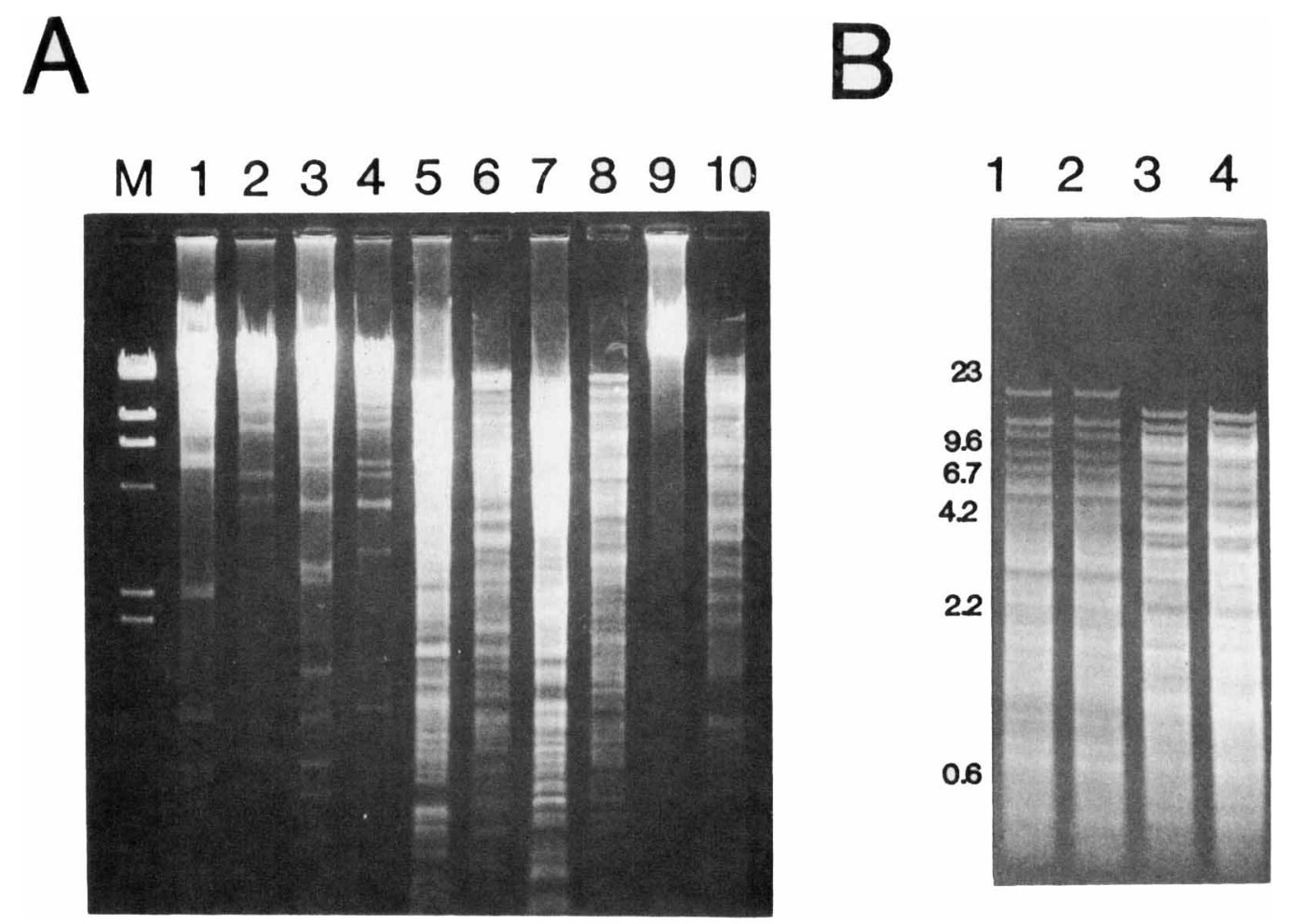

FIG. 1. Restriction digests of $M$. hyopneumoniae and $M$. flocculare DNAs. DNAs were prepared from mycoplasma cells and subjected to restriction digestion and gel electrophoresis as described in the text. (A) Lane M contained HindIII digests of $\lambda$ DNA; the fragments were 23, 9.6, 6.7, 4.2, 2.2, and 1.9 kilobases long. Lanes 1, 3, 5, 7, and 9 contained SmaI, BamHI, HindIII, EcoRI, and BclI digests of $M$. hyopneumoniae DNA, respectively; lanes 2, 4, 6, 8, and 10 contained SmaI, BamHI, HindIII, EcoRI, and BclI digests of $M$. flocculare DNA, respectively. (B) Lanes 1 and 2 contained $M s p I$ and $H p a I I$ digests of $M$. hyopneumoniae DNA, respectively. Lanes 3 and 4 contained $M s p I$ and HpaII digests of M. flocculare DNA, respectively. The sizes (in kilobases) of HindIII-cleaved $\lambda$ DNA fragments are indicated on the left. 


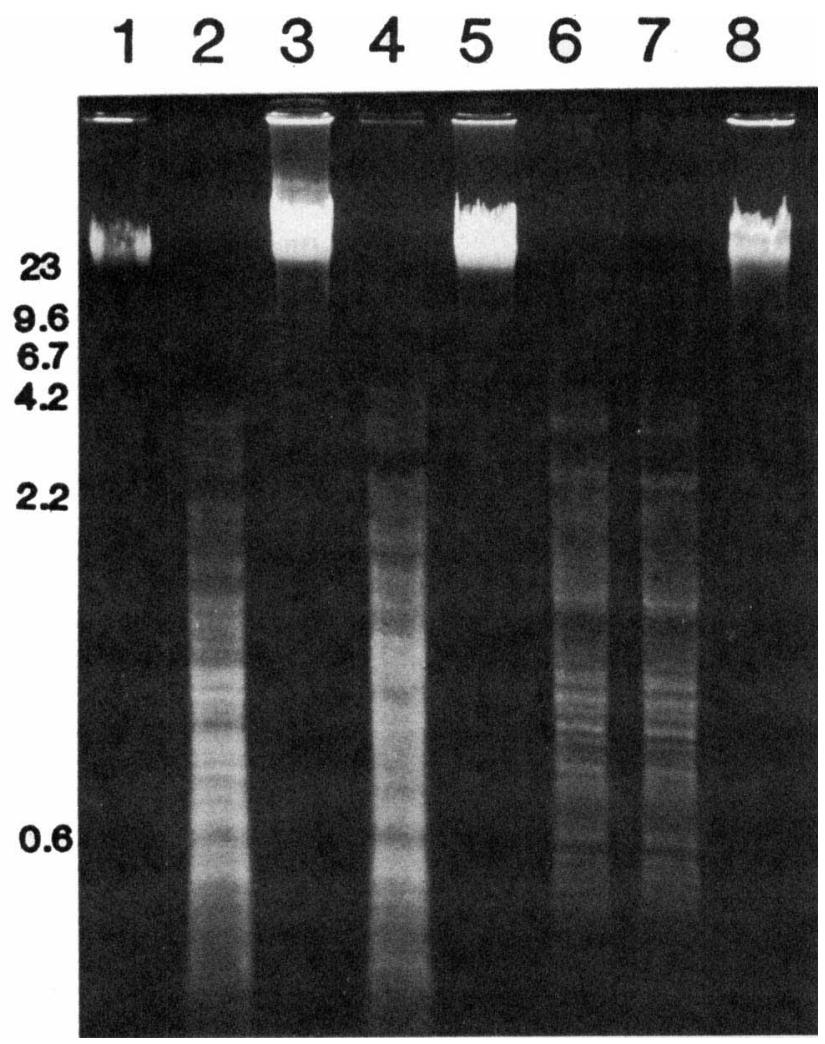

FIG. 2. Evaluation of DNA methylation in two porcine mycoplasmas by using restriction endonuclease isoschizomers. Uncleaved DNAs (lanes 1 and 5) and Sau3A (lanes 2 and 6), MboI (lanes 3 and 7), and $D p n I$ (lanes 4 and 8) digests of DNAs from $M$. hyopneumoniae (lanes 1 through 4 ) and $M$. flocculare (lanes 5 through 8 ) were analyzed by agarose gel electrophoresis. The sizes (in kilobases) of HindIII-cleaved $\lambda$ DNA fragments are indicated on the left.

flocculare with $D p n \mathrm{I}, M b o \mathrm{I}$, and $\operatorname{Sau} 3 \mathrm{~A}(6,10,23)$, three restriction endonuclease isoschizomers which are particularly useful in evaluating the state of adenine methylation. Consistent with the $B c l$ l cleavage results, DNA from $M$. hyopneumoniae resisted digestion by $M b o I$, an enzyme which cleaves at GATC only when adenine is not methylated. In contrast, cleavage was obtained with both Sau3A, which cleaves at GATC regardless of whether adenine is methylated, and DpnI, which cleaves only if the adenine in GATC is methylated. These results suggest that the adenine nucleotide in GATC from $M$. hyopneumoniae strain $\mathrm{J}^{\mathrm{T}}$ is methylated. On the other hand, $M$. flocculare DNA was equally susceptible to cleavage by $M b o I$ and $S a u 3 A$, and thus the GATC sequence is not methylated to any appreciable extent.

To ascertain whether methylation of the adenine nucleotide of the GATC sequence is common among strains of $M$. hyopneumoniae, DNAs from three other strains of this organism (strains 11, 1361A, and 1375C) were prepared and analyzed with $D p n I, M b o I$, and $S a u 3 A$. Our results indicate that the DNAs from all four strains of $M$. hyopneumoniae tested appear to contain $\mathrm{N}^{6}$-methyladenine in GATC.

$M$. hyopneumoniae cells recovered from infected pigs also contain methylated DNA. Total DNA was prepared from lung washings of $M$. hyopneumoniae-infected pigs and cleaved with either DpnI, MboI, or Sau3A. Southern blot hybridization was performed as described above (Fig. 3). Consistent with the results obtained with in vitro-grown cells of $M$. hyopneumoniae, $M$. hyopneumoniae cells recovered from infected animals also contained methylated bases ( $\left.\mathrm{G}^{\mathrm{m}} \mathrm{ATC}\right)$ in their DNA. The radioactive probe used in these experiments also hybridized with $M$. flocculare DNA. Although the DNA fragment sizes were different for the two mycoplasmas, the strong intensity of hybridization with both species indicated that in at least a portion of their genomes, the two species share a high degree of homology in their nucleotide sequences.

\section{DISCUSSION}

The small sizes of the genomes of mycoplasmas, as well as their low guanine-plus-cytosine contents (17), facilitates analysis of their DNAs by restriction enzyme digestion. Restriction enzymes which recognize guanine-plus-cytosinerich sequences are particularly useful since they generate a relatively small number of DNA fragments which can then be resolved by gel electrophoresis.

Sequence-specific methylation is quite common among the procaryotes. The DNA may be methylated at either the

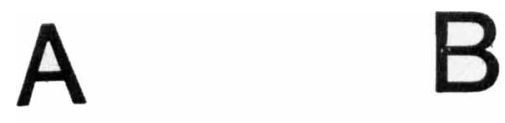

1

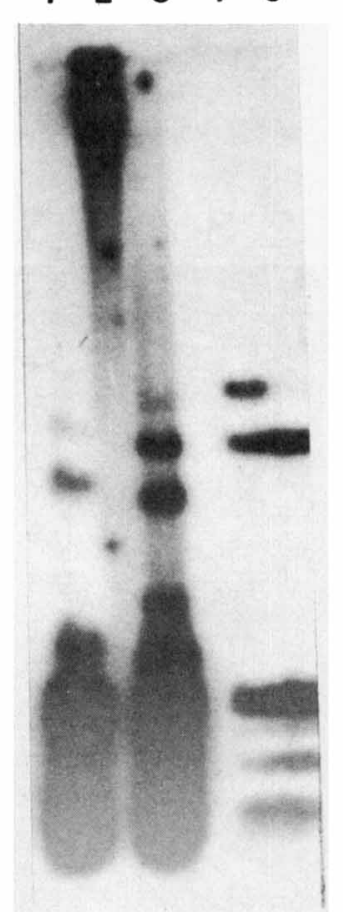

123

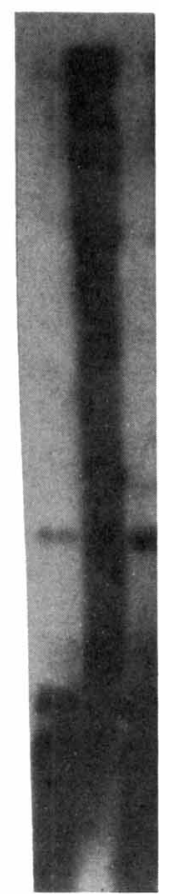

FIG. 3. Hybridization of mycoplasmal DNAs to a $M$. hyopneumoniae recombinant DNA probe. (A) DNAs prepared from in vitrocultured $M$. hyopneumoniae cells (lanes 1 through 3 ) and $M$. flocculare cells (lanes 4 and 5) were cleaved with Sau3A (lanes 1 and 4), MboI (lanes 2 and 5), and DpnI (lane 3) and analyzed by blot hybridization as described in the text. (B) DNA prepared from lung washings of $M$. hyopneumoniae-infected pigs was cleaved with Sau3A (lane 1), MboI (lane 2), and DpnI (lane 3). Southern blot hybridization was performed as described in the text. 
adenine residue $\left(\mathrm{N}^{6}\right.$-methyladenine) or at the cytosine residue (5-methylcytosine) (18). The biological significance of methylation of DNA has not been determined. Although some sequence-specific methylation is clearly part of the restriction-modification phenomenon in bacteria $(7,24)$, other sequence-specific methylation, such as that induced by the $E$. coli dam gene (15) (which methylates adenine in the GATC sequence), is not associated with restriction modification. The dam methylase is believed to play a role in postreplication mismatch repair (11).

DNA from some mycoplasmas has been reported previously to contain methylated bases (19). The extent of methylation of adenine residues in mycoplasmal DNA has been reported to range from 0.2 to $2 \%$. It has also been reported that $5.8 \%$ of the cytosine residues in Mycoplasma hyorhinis DNA are methylated (19). Acholeplasma laidlawii strain K2 has also been reported to have methylated cytosine in its GATC sequence (8).

Whether the sequence-specific methylation which we describe in DNA from $M$. hyopneumoniae is associated with a restriction-modification system or is part of a methylation pathway similar to that in $E$. coli dam is unclear at this point. One restriction enzyme, ThaI, has been isolated from Thermoplasma acidophilum (16). T. acidophilum is a wall-less procaryote similar to the mycoplasmas but differs substantially from all other members of the Mollicutes. Thus, whether $M$. hyopneumniae or other members of the Mollicutes produce restriction enzymes is of great interest and awaits further study.

As suggested by Bové and Saillard (3), restriction enzyme analysis of mycoplasmas provides a useful procedure for additional characterization of mycoplasmas. As illustrated in the present study, $M$. hyopneumoniae and $M$. flocculare can be clearly distinguished by comparing electropherograms of DNA digests. This comparison was suggested recently by the Board of the International Research Program on Comparative Mycoplasmology.

The distinctiveness of the patterns of digests from $M$. hyopneumoniae and $M$. flocculare supports the serological evidence obtained by metabolic inhibition tests that these two species are indeed distinct. Obviously, DNA-DNA hybridization must be performed before reaching a definite conclusion as to the degree of genetic relatedness between these two mycoplasma species. Although $M$. hyopneumoniae and $M$. flocculare share a common habitat (the porcine respiratory tract), they differ in that $M$. hyopneumoniae is a very important pathogen, whereas $M$. flocculare is apparently without pathogenic potential.

Our ability to detect mycoplasmas in clinical material (i.e., lung washings) by using a nick-translated cloned mycoplasma DNA probe may be of interest to workers in the field. The scarcity of biochemical asssays for mycoplasmas renders diagnosis of mycoplasmal infections difficult. Thus, the use of DNA probes offers an easy and sensitive detection method.

\section{ACKNOWLEDGMENTS}

We thank Hela Pettegrew and Barbara Zimmermann for technical assistance.

\section{LITERATURE CITED}

1. Bingham, A. H. A., T. Atkinson, D. Sciaky, and R. J. Roberts. 1978. A specific endonuclease from Bacillus caldolyticus. Nucleic Acids Res. 5:3457-3467.

2. Boliver, F., R. L. Rodriguez, P. J. Greene, M. C. Betlach, H. L.
Heyneker, and H. W. Boyer. 1977. Construction and characterization of new cloning vehicles. Il. A multipurpose cloning system. Gene 2:95-113.

3. Bové, J. M., and C. Saillard. 1979. Cell biology of spiroplasmas, p. 83-153. In R. F. Whitcomb and J. G. Tully (ed.), The mycoplasmas, vol. 3. Academic Press, Inc., New York.

4. Cerone-Mclernon, A. M., and G. Furness. 1980. The preparation of transforming DNA from Mycoplasma hominis strain Sprott tet $^{\mathrm{r}}$ and quantitative studies of the factors affecting the genetic transformation of Mycoplasma salivarium strain S9 tet ${ }^{\mathrm{s}}$ to tetracycline resistance. Can. J. Microbiol. 26:1147-1152.

5. Denhardt, D. T. 1966. A membrane-filter technique for the detection of complementary DNA. Biochem. Biophys. Res. Commun. 23:641-646.

6. Dreiseikelmann, B., R. Eichenlaub, and W. Wackernagel. 1979. The effect of differential methylation by Escherichia coli of plasmid DNA and phage T7 and $\mathrm{DNNA}$ on the cleavage by restriction endonuclease Mbo I from Moraxella bovis. Biochim. Biophys. Acta 562:418-428.

7. Duhorlein, V., S. Linn, and W. Arber. 1969. Host specificity of DNA produced by Escherichia coli. XI. In vitro modification of phage fd replicative form. Proc. Natl. Acad. Sci. U.S.A. 63:556-562.

8. Dybrig, K., D. Swinton, J. Maniloff, and S. Hattman. 1982. Cytosine methylation of the sequence GATC in a mycoplasma. J. Bacteriol. 151:1420-1424.

9. Friis, N. F. 1975. Some recommendations concerning primary isolation of Mycoplasma suipneumoniae and Mycoplasma flocculare: a survey. Nord. Veterinaermed. 27:337-339.

10. Geier, G. E., and P. Modrich. 1979. Recognition sequence of the dam methylase of Escherichia coli K-12 and mode of cleavage of Dpn I endonuclease. J. Biol. Chem. 254:1408-1413.

11. Glickman, B. W., P. Vandel Elsen, and M. Radman. 1978. Induced mutagenesis in dam mutants of Escherichia coli: a role for 6-methyladenine residues in mutation avoidance. Mol. Gen. Genet. 163:307-312.

12. Israel, M. A., D. F. Vanderryn, D. F. Meltzer, and M. A. Martin. 1980. Characterization of polyoma viral DNA sequences in polyoma induced hamster tumor cell lines. J. Biol. Chem. 255:3798-3805.

13. Jeffreys, A. J., and R. A. Flavell. 1977. A physical map of the DNA regions flanking the rabbit B-globin gene. Cell 12:429-439.

14. Mandel, M., and A. Higa. 1970. Calcium-dependent bacteriophage DNA infection. J. Mol. Biol. 53:159-162.

15. Marinus, M. G. 1973. Location of DNA methylation genes on the Escherichia coli K-12 genetic map. Mol. Gen. Genet. 127:47-55.

16. McConnell, D., D. Searcy, and G. Sutcliffe. 1978. A restriction enzyme Tha I from the thermophilic mycoplasma Thermoplasma acidophilum. Nucleic Acids Res. 5:1729-1739.

17. Morowitz, H. J., and D. C. Wallace. 1973. Genome size and life cycle of the mycoplasma. Ann. N.Y. Acad. Sci. 225:62-73.

18. Razin, A. 1978. Methylated bases in the single-stranded DNA phages, p. 165-175. In D. T. Denhardt, D. Dressler, and D. S. Ray (ed.), The single-stranded DNA phages. Cold Spring Harbor Monograph Series. Cold Spring Harbor Laboratory, Cold Spring Harbor, N.Y.

19. Razin, A., and S. Razin. 1980. Methylated bases in mycoplasmal DNA. Nucleic Acids Res. 8:1383-1390.

20. Razin, S., R. Harasawa, and M. F. Barile. 1983. Cleavage patterns of the mycoplasma chromosome, obtained by using restriction endonucleases, as indicators of genetic relatedness among strains. Int. J. Syst. Bacteriol. 33:201-206.

21. Razin, S., J. G. Tully, D. L. Rose, and M. F. Barile. 1983. DNA cleavage patterns as indicators of genotypic heterogeneity among strains of Acholeplasma and Mycoplasma species. J. Gen. Microbiol. 129:1935-1944.

22. Rigby, P. W. J., M. Dieckmann, C. Rhodes, and P. Berg. 1977. Labeling deoxyribonucleic acid to high specific activity in vitro by nick translation with DNA polymerase I. J. Mol. Biol. 113:237-251.

23. Roberts, R. J. 1980. Restriction and modification enzymes and their recognition sequences. Gene 8:329-343. 
24. Roberts, R. J. 1981. Restriction and modification enzymes and their recognition sequences. Nucleic Acids Res. 9:Y75-Y96.

25. Rose, D. L., J. G. Tully, and R. G. Wittler. 1979. Taxonomy of some swine mycoplasmas: Mycoplasma suipneumoniae Goodwin et al. 1965, a later, objective synonym of Mycoplasma hyopneumoniae Mare and Switzer 1965, and the status of Mycoplasma flocculare Meyling and Friis 1972. Int. J. Syst.
Bacteriol. 29:83-91.

26. Southern, E. M. 1975. Detection of specific sequences among DNA fragments separated by gel electrophoresis. J. Mol. Biol. 98:503-517.

27. Whittlestone, P. 1979. Porcine mycoplasmas, p. 133-176. In J. G. Tully and R. F. Whitcomb (ed.), The mycoplasmas, vol. 2. Academic Press, Inc., New York. 